\title{
Necessidades de mães de bebês internados em UTI Neonatal de uma maternidade privada
}

\section{Needs of mothers of babies admitted to the neonatal ICU of a private maternity hospital}

DOI: $10.46919 / \operatorname{arch} 2 \mathrm{n} 5-001$

Recebimento dos originais: 01/04/2021

Aceitação para publicação: 30/06/2021

\author{
Alline Silva Pimentel Barcellos \\ Especialista em Psicologia da Saúde e Hospitalar \\ Especialista em Psicopatologia Clínica \\ Instituto de Ensino e Pesquisa - Associação de Combate ao Câncer em Goiás \\ End.: Avenida Circular, número 693, apto 1103-B- Edifício Vaza Barris \\ Goiânia -Goiás CEP 74823-020 \\ E-mail: allinepim@ hotmail.com \\ Geovanna Porto Inácio \\ Graduada em Medicina \\ Instituto de Neurologia de Goiânia \\ End.: Rua T-28, número 1477, apto 3204 - Edifício Pontal Ecolife \\ Goiânia - Goiás CEP 74215-040 \\ E-mail: amgeovannapi@gmail.com

\section{Joana D’Arc Silvério Porto} \\ Hospital das Clínicas da Universidade Federal de Goiás \\ Doutora em Ciências da Saúde \\ End.: Rua T-28, número 1477, apto 3204 - Edifício Pontal Ecolife \\ Goiânia - Goiás CEP 74215-040 \\ E-mail: portojoana@ hotmail.com
}

\begin{abstract}
RESUMO
A hospitalização do bebê na Unidade de Terapia Intensiva Neonatal (UTI Neo) pode ser acompanhada de momentos de instabilidade, insegurança e rupturas na relação mãe-bebê. A mãe tem um papel importante no desenvolvimento e recuperação do bebê nesta unidade. Desse modo são imprescindíveis a atenção e o cuidado com essas mães. Esta pesquisa identificou a importância e a satisfação das necessidades de mães com bebês internados na UTI Neo de uma maternidade particular. Participaram15 mães, com idade média 28 anos. Os instrumentos utilizados para a coleta de dados foram: questionário sociodemográfico e o Inventário de Necessidades e Estressores de Familiares em Terapia Intensiva (INEFTI). Os resultados evidenciaram que as mães avaliaram as cinco dimensões segurança, proximidade, informação, conforto e suporte como muito importantes a importantíssimas. No entanto, alguns itens demonstraram insatisfação, principalmente no que se refere ao conforto. Espera-se que esses resultados possam atender as necessidades das mães ao favorecer o diálogo, o cuidado e criar melhores condições de acolhimento e de espaço físico para amenizar o sofrimento advindo desse período de internação do bebê na UTI Neo.
\end{abstract}

Palavras-Chave: Unidade de terapia intensiva neonatal, bebês, mães, necessidades 


\section{ABSTRACT}

The hospitalization of the baby in the Neonatal Intensive Care Unit (Neo ICU) may be accompanied by moments of instability, insecurity and ruptures in the mother-baby relationship. The mother plays an important role in the baby's development and recovery in this unit. Thus, attention and care to these mothers are essential. This research identified the importance and satisfaction of the needs of mothers with babies admitted to the Neo ICU of a private maternity hospital. Fifteen mothers, mean age 28 years, participated. The instruments used for data collection were: a sociodemographic questionnaire and the Inventory of Needs and Stressors of Families in Intensive Care (INEFTI). The results showed that the mothers evaluated the five dimensions safety, closeness, information, comfort and support as very important to very important. However, some items showed dissatisfaction, especially regarding comfort. It is expected that these results may meet the mothers' needs by favoring dialogue, care and creating better conditions for welcoming and physical space to ease the suffering resulting from this period of hospitalization of the baby in the Neo ICU.

Key words: neonatal intensive care unit, babies, mothers, needs.

\section{INTRODUÇÃO}

Os cuidados com os bebês prematuros tornaram-se mais proeminente no século XIX. Esperava-se que os bebês prematuros e malformados morressem, pois se acreditava unicamente que a seleção natural se encarregaria dos bebês menos adaptados. A partir de 1960 o local a onde os bebês prematuros ficavam internados, passou a ser denominada Unidade de Tratamento Intensivo Neonatal (UTINeo).

A prematuridade é avaliada para os neonatos, os bebês que nascem antes de completarem 37 semanas de gestação, e um aspecto importante a ser considerado é que tornou questão de saúde pública, global e complexa. A estimativa é de que cerca de 15 milhões de neonatos prematuros nascem por ano, e a tendência é de crescimento. Essa taxa no Brasil em 2014, foi de 11,18\%, o que o faz entre os dez países do mundo com maior número de nascimentos prematuros (WHO, 2018; AZEVEDO, PFEIL, 2019).

No Brasil, mesmo no século XXI, encontramos um cenário muito distante do ideal e é considerado atrasado em relação a outros países, quanto ao processo de organização da rede de assistência neonatal. O acesso ao conjunto de intervenções neonatais com um padrão comparável aos melhores centros do mundo tem sido encontrado apenas em algumas unidades do setor privado e em algumas unidades públicas de maior complexidade, na qual, geralmente ligadas a instituições de ensino e pesquisa (CARVALHO; GOMES, 2005).

O bebê que nasce prematuro ou doente e necessita de assistência especializada, causa impacto em toda família. O bebê "real" não corresponde ao bebê imaginário, idealizado durante a gestação, principalmente para a mãe, e isso pode ser devastador, tornando um desafio para os pais a adaptação ao novo papel, às necessidades do filho e às demandas sociais. Na UTINeo, a separação que é imposta pelo tratamento e equipamentos impede o contato e dificulta o vínculo que se forma entre pais e os bebês saudáveis, já nos primeiros instantes após o parto. (ARAÚJO; SOUZA, 2015) 
As formas de cuidar do recém-nascido $(\mathrm{RN})$ enfermo evoluíram graças às novas tecnologias que possibilitaram a sobrevida de diversos bebês. Portanto, esse avanço levou a transformar o bebê em objeto de cuidado. A doença e o tratamento eram o foco da assistência, e os pais em apenas meros expectadores.

Nos tempos atuais, voltou-se a discutir não somente a sobrevivência do bebê, mas também as conseqüências provocadas pela internação, que é vivida em uma fase inicial do desenvolvimento para a vida do bebê e de sua família. A hospitalização provoca ainda, a separação do bebê e suas mães, em um momento em que a proximidade é fundamental para estabelecer o vínculo e conseqüentemente influenciando no desenvolvimento da criança (SANTOS, 2015).

É importante verificar e responder às preocupações das mães, procurando explicar de forma simples e concreta o estado de saúde e o tratamento e equipamentos usados no bebê, buscando dar ênfase ao bebê, e não à doença.

Atentos às necessidades da mãe, a equipe precisa estar sensibilizada em relação a ela e interagir, identificando suas necessidades e demandas. É importante que as mães se sintam acolhidas na UTI neonatal e saibam que sua presença é bem-vinda. Sendo importante também que a instituição forneça estratégias de enfrentamento para família e equipe, criando grupos de apoio para as mães, acesso psicológico clínico, reunião com a equipe multiprofissional e sugestão para receberem o apoio religioso de sua opção (ARAÚJO; SOUZA, 2015).

O desenvolvimento do apego mãe-bebê se dá a partir da comunicação, e baseia-se fundamentalmente na capacidade da mãe decodificar os sinais emitidos pelo bebê e essa interação iniciase dede a gestação, sendo assim uma preparação psicológica para o acolhimento desta nova vida. A mãe ao sentir essas emoções, também sente a necessidade de ser acolhida nas suas necessidades.

Com o nascimento do bebê, inicia-se uma nova fase neste processo de vínculo. Agora não é mais o bebê idealizado, mas o bebê real. E esse processo de vínculo sofre sérias interferências, no caso de bebês prematuros, com complicações ou malformados. Iniciando um conflito sobre a capacidade de apegar-se a esse bebê ou não? Teria a mãe capacidade de apego e depois perdê-lo ou seria melhor não se apegar? (GRANDA, 1998).

Nos bebês internados em UTINeo, percebe-se que há uma variação na expressão de atitudes e comportamentos, isso de acordo com o tipo de cuidado que é dispensado a eles, principalmente a forma que esses cuidados são executados e da pessoa que os executa. Podendo ser observado nos recém-nascidos, a partir das suas primeiras horas de vida a diferença nas suas reações, expressas, em relação a um toque delicado, firme e seguro. Ou quando o cuidador demonstra atenção, carinho e amparo, através de conversa, demonstrando ao bebê que está atento quanto as suas necessidades e não apenas executando tarefas autônomas e programadas. 
Uma das formas de expressão é o choro. Quando o bebê chora profundamente, este choro revela uma necessidade. Deve-se observar se este bebê está alimentado, higienizado e se revela alguma dor física. Sendo observadas essas hipóteses e ainda assim o choro persistir, verifica-se que ele apresenta sentimento de desamparo e abandono. Pode-se comprovar este fato, quando a mãe ou o cuidador se próxima e o acolhe em seus braços ou fala com ele, embalando-o ao som de uma cantiga.

Então, o bebê vai se aquietando aos poucos e muitas vezes dorme retomando assim ao estado de segurança e conforto. Pode ser observado ainda que o bebê pode não se aquietar, quando segurado e manipulado por uma pessoa que não oferece essa segurança e acolhimento que ele necessita.

Winnicot (1993, apud GRANDA, 1998), destaca a respeito da identificação dos bebês com suas mães, e descreve três funções deste estágio inicial de desenvolvimento perinatal: holding, que traduz o segurar, a boa qualidade do contato físico, que é tão necessária para o recém-nascido nos primeiros estágios do desenvolvimento. Quando este contato não é satisfatório e ineficiente, pode causar no bebê uma grande sensação de angústia, desamparo, desconforto interno e ansiedade patológica. Já quando esta manipulação é satisfatória, promove o desenvolvimento da coordenação motora, tônus muscular e contribui para o sentido do real.

Spitz (1998, apud SANTOS, 2015) ressalta que distúrbios emocionais, estão associados à relação inadequada ou insuficiente entre mãe e filho. Quando priva o bebê da presença de sua mãe ou um substituto a altura, é como se estivesse privando a criança de algo vital.

Percebemos que o distanciamento ou o não envolvimento da mãe na internação do bebê, pode gerar dificuldades no desenvolvimento e saúde, pois a recuperação e o bom desenvolvimento do bebê não dependem unicamente de cuidados profissionais, mas também dos cuidados e do carinho de seus pais. A UTINeo deve estar preparada para amparar as mães, reduzir o estresse e favorecer a interação mãe-bebê (COSMO et al, 2014).

A assistência humanizada precisa ser parte da evolução da ciência, onde se reconhece as peculiaridades do bebê e as necessidades das mães, que devem ser consideradas como parte integrante do cuidado. Pensando assim, algumas intervenções são recomendadas e implantadas em unidades neonatais, com o objetivo de minimizar o estresse para o trinômio bebê-família-equipe. Proporcionando interações positivas e com qualidade para todos (ARAÚJO; SOUZA, 2015).

O ambiente deve ser planejado e constantemente aperfeiçoado no sentido de favorecer o bem-estar de todos (equipe, família e bebê). Levando em consideração as limitações de uma UTINeo, este ambiente tem que ser o mais agradável e confortável possível, tanto para os bebês (pacientes), para as mães e familiares, quanto para a equipe. E tornar a UTINeo mais humanizada, não envolve altos gastos, depende de interesse, boa vontade e criatividade por parte das pessoas envolvidas no atendimento a saúde dos bebês. 
Outro aspecto importante é permitir a permanência das mães com o bebê o maior tempo possível, estimulálas a tocar, conversar com os bebês, a participar dos cuidados diários, como trocar fralda, dar banho.

Uma UTINeo (UTI Neonatal) deverá oferecer condições mínimas de conforto, com espaços destinados a permanência da mãe ao lado do leito, para descanso, alimentação, higiene e acomodação de objetos, entre outros (ARAÚJO; SOUZA, 2015).

Identificar as necessidades das mães dos bebês internados em uma UTINeo contribuirá para uma conscientização de que o cuidado com a mãe faz parte do cuidado integral para com o paciente, neste caso o RN.

Sabendo as necessidades dessas mães e as suprindo, estaremos "dando as mãos" para a humanização, que levará consigo e facilitará o desenvolvimento e fortalecimento do apego, amparo e vínculo mãe-bebê, bebê-mãe, que como pode-se observar, é à base da saúde física, psíquica, social e espiritual (bio-psico-socio-espiritual) desse bebê e desta mãe, que pelo processo em si da internação, já sofreram seus traumas e sequielas característicos deste advento. A partir deste pressuposto o objetivo do estudo foi avaliar as necessidades das mães de bebês internados na UTI Neo de uma maternidade privada.

\section{MÉTODO}

A amostra do estudo foi composta por quinze mães de bebês internados na UTI Neonatal de uma maternidade particular, na cidade de Goiânia, eram maiores de 18 anos e que já tinham realizado uma visita. Este estudo foi aprovado pelo Comitê de Ética da Associação de Combate ao Câncer de Goiás- ACCG parecer $\mathrm{n}^{\mathrm{o}} 1.714 .316$

Foram excluídas as mães que apresentaram algum tipo de transtorno psiquiátrico e que inviabilizou a compreensão no momento da aplicação do Inventário de Necessidades e Estressores de Familiares de Terapia Intensiva- INEFTI, participantes surdas, uma vez que a aplicação foi realizada pela leitura dos instrumentos pela pesquisadora para as participantes e as mães de bebês que estavam com possível alta prescrita para as próximas 12 horas. Pois como foi constatado no questionário piloto, este evento interfere nas repostas.

A coleta de dados foi realizada na sala de espera e ordenha da UTI Neonatal nos meses de setembro e outubro de 2016, em uma maternidade privada. As participantes foram abordadas individualmente e os instrumentos utilizados foram: a) o Questionário sociodemográfico para identificar características como: idade, escolaridade, estado civil, naturalidade, religião, profissão, número de filhos, história de aborto, experiência anterior com parentes na UTI, conhecimento do diagnóstico clínico do paciente, tempo de internação, com quantas semanas o bebê nasceu; b) o Inventário de Necessidades e Estressores de Familiares em Terapia Intensiva (INEFTI) adaptado e validado para a cultura brasileira por Castro (1999) que avalia a importância das necessidades de familiares de pacientes em UTI e a satisfação como 
atendimento nesta unidade. Após discussão entre as autoras foi elaborada uma pergunta para complementar os objetivos do estudo abordando a participante/mãe: "Você acrescentaria algo a este questionário? O que seria?" Apesar do INEFTI ser desenvolvido para abordar familiares de pacientes internados na UTI adulto, as autoras analisaram e avaliaram a importância de sua utilização na pesquisa, com mães de bebês internados na UTI Neo, uma vez que não existe até o momento um instrumento específico para avaliar as necessidades destas mães nesta unidade. Um estudo piloto foi realizado com a aplicação deste instrumento para constatar a eficiência, segurança ou algum tipo de viés que prejudicasse a pesquisa. Após o estudo piloto verificou-se que o instrumento pode ser eficaz para essa população. O INEFTI contém cinco dimensões: Informação, Segurança, Proximidade, Suporte e Conforto, a versão disponível em português é composta por 43 itens. A escala de medida utilizada varia de um a quatro pontos. O original do instrumento é apresentado em uma única folha que contém os 43 itens com uma coluna a direita com os domínios importância e satisfação. Para o domínio importância a pontuação equivale, 1-não importante, 2- pouco importante, 3 - muito importante, 4- importantíssimo. E quanto a satisfação a pontuação equivale, 1insatisfeito, 2- pouco satisfeito, 3- muito satisfeito, 4- totalmente satisfeito.

No entanto, conforme constatado no estudo piloto, quando apresentado os 43 itens com os domínios importância e satisfação ao mesmo tempo, possibilitou que as participantes se confundissem no momento de avaliar tais domínios. Fato este descrito no estudo de Solimani, Porto e Sousa (2015). Assim este estudo foi desenvolvido apresentando as participantes os mesmos 43 itens, mantendo os domínios a direita, porém com os itens e domínio importância e itens com domínio satisfação em folha separada.

Os dados foram avaliados por média, desvio-padrão e frequência pelo programa Microsoft Excel versão 13.

\section{RESULTADOS}

Participaram 15 mães de bebês internados na UTI Neonatal de uma maternidade particular. Os resultados da análise do perfil sociodemográfico apresentaram uma idade média de 28 anos, na faixa etária de 21 a 40 anos, a maioria com escolaridade do ensino médio ao superior (67\%). Em relação à religião 60\% eram católicas e o estado civil $60 \%$ casadas, $73 \%$ tinham emprego, já tinham pelo menos um filho (73,34\%), e 26,66\% só tinham o filho internado na UTI Neo, $53 \%$ das mães relataram terem experiência com um familiar na UTI. A maioria das mães (93\%) conhecia o diagnóstico do seu bebê, não tiveram qualquer tipo de aborto 87\%. E o tempo médio de internação dos bebês foi de 14 dias, onde $77 \%$ eram prematuros, pois nasceram com menos de 37 semanas e $27 \%$ com diagnósticos, como complicação no parto e má formação. 
A Tabela 1- Análise do Inventário de Necessidades e Estressores de Familiares em Terapia Intensiva em mães com bebês internados na Unidade de Terapia Intensiva Neonatal $(\mathrm{N}=15)$ apresenta a análise descritiva de cada item do INEFTI em relação às suas 5 dimensões e seus 2 domínios.

\begin{tabular}{l|l|l|l|l|l|l|l|}
\hline \multirow{2}{*}{ Item } & \multicolumn{3}{|c|}{ Importância } & \multicolumn{3}{c|}{ Satisfação } \\
\hline
\end{tabular}

\section{Segurança}

1 Saber quais as chances de melhora do paciente

5 Ter perguntas respondidas com franqueza

14 Sentir que há esperança de melhora do paciente

17 Estar seguro que o melhor tratamento possível está sendo dado ao paciente

33 Receber explicações que possam ser compreendidas Sentir que o pessoal do hospital se interessa pelo paciente

$\begin{array}{cccccc}14 & 3,933 & 0,258 & 8 & 3,067 & 0,704 \\ 12 & 3,800 & 0,414 & 10 & 3,200 & 0,561 \\ 12 & 3,800 & 0,414 & 9 & 3,400 & 0,507 \\ 13 & 3,867 & 0,352 & 8 & 3,400 & 0,828 \\ 12 & 3,800 & 0,414 & 8 & 2,867 & 0,834 \\ 14 & 3,933 & 0,258 & 7 & 3,267 & 0,884 \\ 14 & 3,933 & 0,258 & 7 & 3,267 & 0,704\end{array}$

\section{Suporte}

2 Ter orientações gerais sobre a UTI na primeira visita

7 Falar sobre sentimentos negativos relacionados ao que está acontecendo

9 Ser informado sobre o que fazer quando estiver ao lado do paciente

12 Ter amigos por perto para apoiá-lo

Ter um lugar em que possa ficar sozinho enquanto estiver no hospital

Ter uma pessoa para orientar em caso de problemas financeiros

24 Ter a visita de alguém da religião a qual pertenço

25 Conversar sobre a possibilidade de morte do paciente

Ser acompanhado (a) por profissional, amigo, ou familiar durante a visita

27 Ter alguém que se preocupe com a minha saúde

Sentir-se à vontade para demonstrar meus sentimentos e emoções

31 Saber quais os outros profissionais podem me ajudar

35 Ser informado sobre serviços religiosos

$\begin{array}{cccccc}13 & 3,867 & 0,352 & 5 & 2,733 & 1,033 \\ 7 & 3,133 & 0,990 & 9 & 3,000 & 0,655 \\ 10 & 3,600 & 0,632 & 9 & 3,200 & 0,775 \\ 9 & 3,467 & 0,743 & 6 & 2,733 & 1,100 \\ 5 & 2,667 & 1,113 & 6 & 2,200 & 1,146 \\ 9 & 2,867 & 0,640 & 7 & 2,200 & 1,082 \\ 5 & 2,933 & 0,961 & 7 & 2,933 & 0,884 \\ 11 & 3,533 & 0,915 & 6 & 3,133 & 0,915 \\ 12 & 3,667 & 0,724 & 4 & 2,600 & 1,121 \\ 7 & 3,267 & 0,799 & 7 & 2,733 & 0,704 \\ 8 & 3,267 & 0,799 & 8 & 3,200 & 0,676 \\ 8 & 3,533 & 0,516 & 9 & 2,933 & 0,799 \\ 5 & 2,667 & 1,047 & 8 & 2,733 & 1,033\end{array}$

\section{Informação}

3 Poder conversar com o médico todos os dias

4 Ter uma pessoa que possa dar informações por telefone

11 Saber quem pode dar a informação que necessito

Saber porque determinados tratamentos foram realizados com o paciente

Saber quais os profissionais que estão cuidando do paciente

Saber que tratamento médico está sendo dado ao paciente

19 Saber exatamente o que está sendo feito para o paciente

36 Ajudar a cuidar do paciente na U.T. I

$\begin{array}{cccccc}13 & 3,867 & 0,352 & 9 & 3,467 & 0,743 \\ 9 & 3,467 & 0,743 & 5 & 2,467 & 1,060 \\ 9 & 3,533 & 0,640 & 8 & 2,600 & 0,986 \\ 12 & 3,800 & 0,414 & 7 & 3,267 & 0,884 \\ 10 & 3,667 & 0,488 & 6 & 3,000 & 1,069 \\ 12 & 3,800 & 0,414 & 7 & 3,067 & 0,884 \\ 14 & 3,867 & 0,516 & 7 & 3,267 & 0,704 \\ 8 & 3,333 & 0,816 & 7 & 2,600 & 0,910\end{array}$




\begin{tabular}{|c|c|c|c|c|c|c|c|}
\hline & Proximidade & & & & & & \\
\hline 6 & Ter horário de visita modificado em casos especiais & 8 & 3,400 & 0,737 & 9 & 2,400 & 0,828 \\
\hline 10 & Ser permitido visitar o paciente a qualquer hora & 6 & 2,800 & 1,207 & 5 & 2,267 & 1,100 \\
\hline 29 & Conversar com a mesma enfermeira todos os dias & 8 & 3,333 & 0,816 & 8 & 2,533 & 1,125 \\
\hline 34 & Começar a visita na hora marcada & 11 & 3,667 & 0,617 & 10 & 3,133 & 0,743 \\
\hline 37 & Ser comunicado sobre possíveis transferências & 12 & 3,800 & 0,414 & 12 & 3,067 & 0,458 \\
\hline 38 & $\begin{array}{l}\text { Ser avisado em casa sobre mudanças na condição do } \\
\text { paciente }\end{array}$ & 12 & 3,667 & 0,724 & 9 & 2,667 & 0,976 \\
\hline 39 & $\begin{array}{l}\text { Receber informações sobre o paciente no mínimo uma } \\
\text { vez ao dia }\end{array}$ & 14 & 3,933 & 0,258 & 7 & 3,400 & 0,632 \\
\hline 42 & Ver o paciente freqüentemente & 12 & 3,800 & 0,414 & 5 & 2,533 & 1,246 \\
\hline \multirow[t]{2}{*}{43} & Ter sala de espera perto do paciente & 11 & 3,533 & 0,915 & 7 & 2,667 & 1,047 \\
\hline & Conforto & & & & & & \\
\hline 8 & Ter uma boa lanchonete no hospital & 8 & 3,133 & 0,834 & 10 & 1,533 & 0,834 \\
\hline 20 & Ter móveis confortáveis na sala de espera da U.T. I & 10 & 3,467 & 0,915 & 6 & 2,267 & 1,223 \\
\hline 21 & $\begin{array}{l}\text { Sentir-se aceito pelas pessoas do quadro de } \\
\text { funcionários do hospital }\end{array}$ & 11 & 3,667 & 0,617 & 7 & 3,267 & 0,884 \\
\hline 23 & Ter um telefone perto da sala de espera & 6 & 2,333 & 0,976 & 9 & 2,200 & 1,014 \\
\hline 28 & $\begin{array}{l}\text { Ter certeza que tudo está bem para deixar o hospital } \\
\text { por algum tempo }\end{array}$ & 10 & 3,667 & 0,488 & 7 & 3,133 & 0,743 \\
\hline 32 & Ter um banheiro perto da sala de espera & 11 & 3,733 & 0,458 & 6 & 2,200 & 1,146 \\
\hline
\end{tabular}

Importância: 1-não importante, 2- pouco importante, 3- muito importante, 4- importantíssimo; Satisfação: 1- insatisfeito, 2-pouco satisfeito, 3- muito satisfeito, 4- totalmente satisfeito).

Na Tabela 1 apesar dos itens da dimensão segurança relacionada ao domínio importância apresentarem médias altas, houve um destaque para os itens com média (3,9), são eles: 1) Saber quais as chances de melhora do paciente; 17) estar seguro que o melhor tratamento possível está sendo dado ao paciente, 40) sentir que o pessoal do hospital se interessa pelo paciente e 41) ser informado a respeito de tudo que se relacione a evolução do paciente. Sendo considerados como importantíssimo.

Na dimensão suporte pelo domínio importância, destacamos os itens, os quais as mães consideraram importantíssimo, sendo eles: 02). Ter orientações gerais sobre a UTI na primeira visita $(3,87), 25)$. Conversar sobre a possibilidade de morte do paciente (3,53); 26) Ser acompanhado (a) por profissional, amigo, ou familiar durante a visita $(3,67)$. Concomitantemente, foram pouco importantes, os itens 18). Ter um lugar em que possa ficar sozinho enquanto estiver no hospital $(2,67)$; 24) Ter a visita de alguém da religião a qual pertenço $(2,9)$ e 35) Ser informado sobre serviços religiosos $(2,67)$.

Em relação às médias da dimensão informação pelo domínio importância, quatro foram consideradas importantíssimas com pontuação quase máxima acima de $(3,8)$ os itens 03) Poder conversar com o médico todos os dias, o 13)Saber porque determinados tratamentos foram realizados com o paciente; 15) Saber que tratamento médico está sendo dado ao paciente e 19) Saber exatamente o que está sendo feito 
para o paciente; No entanto, o item 36) Ajudar a cuidar do paciente na UTI foi o que apresentou menor média $(3,3)$.

Para a dimensão proximidade pelo domínio importância, quatro itens tiveram médias altas com pontuação acima de (3,0), os itens: 38 ) Ser avisado em casa sobre mudanças na condição do paciente $(3,67)$, o 37) Ser comunicado sobre possíveis transferências $(3,8)$, o 39) Receber informações sobre o paciente no mínimo uma vez ao dia (3,93), e o 42) Ver o paciente freqüentemente (3,8). E o item 10) Ser permitido visitar o paciente a qualquer hora apresentou pouco importante com a média $(2,8)$.

Na dimensão conforto pelo domínio importância os itens que apresentaram médias altas, destacaram-se quatro: o 20) Ter móveis confortáveis na sala de espera da UTI $(3,46)$; 21) Sentir-se aceito pelas pessoas do quadro de funcionários do hospital $(3,67)$, o 32) Ter um banheiro perto da sala de espera $(3,73)$ e o 28$)$ Ter certeza que tudo está bem para deixar o hospital por algum tempo $(3,67)$.

Ainda, na Tabela 1, agora analisando a dimensão segurança pelo domínio satisfação, destacamos os itens com média acima da pontuação 3,00. Foram esses: 01) Saber quais as chances de melhora do paciente $(3,06)$; o 17) Estar seguro que o melhor tratamento possível está sendo dado ao paciente $(3,4)$; o 40) Sentir que o pessoal do hospital se interessa pelo paciente $(3,26)$ e 41) Ser informado a respeito de tudo que se relacione a evolução do paciente $(3,26)$, estando a metade das participantes satisfeitas.

Na dimensão suporte, analisando o domínio satisfação, a média baixa, abaixo de $(3,0)$ indica pouca satisfação aos itens : 02) Ter orientações gerais sobre a UTI na primeira visita $(2,73)$; 26) Ser acompanhado (a) por profissional, amigo, ou familiar durante a visita $(2,6)$. Observando a baixa satisfação de forma geral da dimensão suporte. Embora a média de satisfação foram altas para os itens 07) Falar sobre sentimentos negativos relacionados ao que está acontecendo $(3,0) ; 09)$ Ser informado sobre o que fazer quando estiver ao lado do paciente $(3,2)$ e 30$)$ Sentir-se à vontade para demonstrar meus sentimentos e emoções $(3,2)$.

Para a dimensão informação pelo domínio satisfação, destaca-se os itens: 03) Poder conversar com o médico todos os dias $(3,46)$, apontando que as mães estão satisfeitas neste aspecto. E demonstrando pouca satisfação nos itens: 04) Ter uma pessoa que possa dar informações por telefone $(2,46)$; 11) Saber quem pode dar informações que necessito $(2,6)$.

Na dimensão proximidade pelo domínio satisfação, podemos observar uma média geral baixa. Destacando os itens 37) Ser comunicado sobre possíveis transferências (3,06); o 38) Ser avisado em casa sobre mudanças na condição do paciente $(2,67)$; o 42) Ver o paciente freqüentemente $(2,5)$ e o item 43) Ter sala de espera perto do paciente $(2,67)$.

A dimensão conforto em relação ao domínio satisfação, apresentaram menores médias os itens: 08) Ter uma lanchonete no hospital $(1,53)$ e o 32$)$ Ter um banheiro perto da sala de espera $(2,2)$. 
A Tabela 2 apresenta as respostas da pergunta acrescentada ao inventário feita as mães: "Você acrescentaria algo a este questionário? O que seria? ". Sobre importância e/ou satisfação de suas necessidades com os seus bebês internados na UTI Neo.

A Tabela 2- Análise dos comentários das necessidades das mães com bebês internados em UTI Neonatal (N=15).

\begin{tabular}{cll} 
Qtd. & Comentário das Mães & Itens \\
1 & $\begin{array}{l}\text { Ter um quarto especial para o pai do Bebê e } \\
\text { durante o tempo que o bebê estiver internado }\end{array}$ & Conforto \\
2 & $\begin{array}{l}\text { Bebedouro na sala de espera } \\
\text { Espaço para as mães e pais que passam o dia no } \\
\text { hospital }\end{array}$ & Proximidade \\
4 & $\begin{array}{l}\text { Oferecer material ou dar manutenção nas } \\
\text { máquinas para ordenha }\end{array}$ & Conforto \\
5 & $\begin{array}{l}\text { Sala climatizada e com entretenimento para os } \\
\text { pais }\end{array}$ & Conforto \\
6 & $\begin{array}{l}\text { Informação sobre a nutrição das mães para } \\
\text { alimentar }\end{array}$ & Informação \\
7 & $\begin{array}{l}\text { Ter um ambiente confortáveis para os pais } \\
\text { Ter reunião pelo menos uma vez por semana } \\
\text { para apoio aos pais }\end{array}$ & Conforto \\
9 & $\begin{array}{l}\text { Deixar que pessoas da família entrem na visita } \\
\text { na ausência do pai ou da mãe }\end{array}$ & Suporte \\
10 & $\begin{array}{l}\text { Má comunicação dos profissionais com a família } \\
\text { Falta de interesse dos profissionais para dar } \\
11\end{array}$ & $\begin{array}{l}\text { Informação } \\
\text { atenção as famílias } \\
12\end{array} \begin{array}{l}\text { Água na sala de espera } \\
\text { Suporte }\end{array}$ \\
\hline
\end{tabular}

As respostas quanto a pergunta acrescentada, manteve a integridade do INEFTI. Nas respostas das participantes, pode-se perceber, que elas utilizaram o espaço para enfatizaram de forma mais objetiva as suas reais necessidades. Apresentaram as necessidades importantes que não são satisfeitas. Os resultados foram apresentados em ordem de maior frequência das dimensões conforto, seguindo de informação, suporte e proximidade. Houve destaque para o conforto, onde $50 \%$ das mães relataram sentir falta de conforto, e em seguida destaca-se a dimensão informação, ressaltando a insatisfação em relação ao recebimento de informação clara emitida a elas.

\section{DISCUSSÃO}

A maioria dos bebês internados na UTI Neo são prematuros ou recém-nascido pré-termo (RNPT), nascido antes de 37 a 41 semanas com malformação congênita e complicações no parto. Portanto, com diagnóstico clínico para internação em UTI Neo.

Ao analisarmos e compreendermos a percepção das mães sobre a importância e a satisfação relacionadas aos cuidados dispensados aos seus bebês, nos possibilitou uma visão da demanda dessas mães para melhorar a humanização na UTI Neo desta instituição. Sousa, Aspásia Basile Gesteira (2015) relatam 
que o acolhimento para receber a família em suas demandas, pretende integrá-la ao ambiente e reduzir as ansiedades e os medos, mas esta possibilidade exige condições mínimas de conforto.

O estudo de Soares, Santos e Gasparino (2010) avaliou a confiabilidade do INEFTI, ao apresentarem valores satisfatórios de consistência interna para o total de itens, sendo que as necessidades julgadas como de maior importância foram aquelas relacionadas à segurança, informações e proximidade. Mostrando que conhecer as necessidades dos familiares permitiu ao profissional de saúde implantar ações (como a capacitação da equipe multiprofissional) para uma melhor relação e assistência aos familiares de pacientes internados nas UTIs. Assim sendo, a importância de uma maternidade/hospital tomar conhecimento dos aspectos relacionados a uma UTI Neo, para poder intervir com mais eficácia. Neste sentido, esse estudo apresentou as necessidades que as mães participantes, julgaram importantes e disseram se estavam satisfeitas em relação à segurança, suporte, informação, proximidade e conforto.

Quanto à variável segurança, esse item avaliou o quanto as mães estão seguras em relação ao tratamento dispensado aos bebês, os itens com maiores médias de importância e de satisfação, refletem a necessidade de segurança que essas mães necessitam para se sentirem bem. De acordo com Araújo \& Souza (2015) e Mathelin (1999), quando há a necessidade de separar o bebê da mãe de forma abrupta ocorre um impacto em toda a família, obrigando a essa mãe a se adaptar a nova rotina social e a lidar com a ansiedade de não ter o filho consigo. As participantes do nosso estudo encontram insatisfeitas com as explicações que lhes são transmitidas, a falta de informação adequada e o uso de "jargões" dificulta à compreensão. A equipe apresenta dificuldades em tirar dúvidas das mães e em conseqüência causam mais ansiedade nelas, e concomitantemente a passividade, a agressividade e/ou a esquiva.

Araújo e Souza (2015) referem que na UTI Neo, os diálogos da equipe com a mãe, muitas vezes são unidirecionais e pontuais, em função do tempo curto e da dificuldade de interação da equipe com a mãe, isso pode se traduzir na dificuldade que a equipe tem de ouvir as dúvidas e questionamentos das mães, como os cuidados com o recém-nascido envolve vários profissionais e especialidades, dentro da UTI Neo.

$\mathrm{Na}$ dimensão suporte, que avaliou como as mães estão recebendo apoio pela maternidade, a maior parte dos itens tiveram médias altas em relação a importância, revelando que a mãe deve ser preparada antes de entrar na UTI Neo. Ser informada como encontrará seu bebê, receber explicações a respeito do quadro clínico, da incubadora, cateteres, sondas, ventilação mecânica pode contribuir positivamente no seu enfrentamento à doença e à hospitalização do bebê, até mesmo diminuir a ansiedade, o medo e receio que as mães têm de tocar o bebê, de desligar algum aparelho, prejudicar o quadro clínico ou de machucar o bebê, caso se aproximem muito.

Em relação à dimensão informação, a qualidade da comunicação da equipe para com as mães, as médias para importância e satisfação demonstraram que as mães estão insatisfeitas em relação ao acesso e as informações claras no que diz respeito ao bebê. Nossos achados vão de encontro com Soares (2007) e 
Bettineli e Erdmann (2009), onde seus estudos também apontaram para a necessidade com o cuidado à família, e principalmente com as mães. Sendo primordial, principalmente quando se refere aos bebês internados em uma UTI Neo. Essas mães necessitam de acesso fácil às informações, a equipe necessita compreender a importância desse aspecto para viabilizar o desenvolvimento de um trabalho integral e humanizado.

A dimensão proximidade avaliou a necessidade da mãe em poder estar próxima ao bebê, todos os itens tiveram médias altas revelando a importância. Uma hipótese para tal dado pode ter relação com as orientações passadas pela equipe, mesmo a UTI Neo, considerada um ambiente hostil muitas vezes, com regras impostas e que são acatadas por parte das mães. Onde a premissa é de que a entrada de muitas pessoas e a qualquer hora nessa Unidade, favoreça a contaminação dos bebês por bactérias é um discurso replicado por essas mães quando questionados sobre a importância desse item.

Enquanto, o domínio satisfação apresentou média geral baixa, expressando a insatisfação das mães em relação a informação do quadro clínico atualizado do bebê e a necessidade de estarem mais próximas a eles. Sendo que a mãe só toma conhecimento do quadro clínico do bebê, durante as visitas. Tais visitas são realizadas uma vez ao dia, com duração de trinta (30) minutos, no caso da mãe que tem filhos gêmeos, esse tempo não é estendido, fazendo com que a mãe tenha que escolher qual dos filhos pegar no colo a cada dia de visita. Assim, a necessidade de humanização nestes ambientes se faz necessária. Destacada por Araújo e Souza (2015) e AMIB (2004) a assistência humanizada leva em consideração as peculiaridades do bebê e as necessidades das mães, que devem ser consideradas como parte integrante do cuidado.

Na dimensão conforto, a média geral foi muito baixa, expressando insatisfação por parte das mães. Estar em um local agradável, que ofereça um mínimo de conforto enquanto aguardam para a ordenha e a visita foi um fator importante para a maioria das mães quanto.

A respostas da questão feita no final do inventário, mostrou que as mães estão insatisfeitas em maioria com relação ao domínio conforto. Elas relataram que ter um espaço climatizado e com entretenimento durante o tempo em que o bebê estiver internado, enquanto permanecem o dia no hospital esperando os horários para ordenha e visita seria muito importante, assim como ter bebedouro de água na sala de espera, pois as mães precisam estar em repouso para a melhor recuperação do parto e para a produção de leite. Relataram a falta de material ou de manutenção nas máquinas para ordenha, pelo fato de não ter máquina para ordenha do leite materno para todas as mães no mesmo horário.

Manifestaram insatisfação em relação às informações dadas pela equipe sobre a dieta restritiva que precisariam fazer por causa de intolerâncias do bebê, provocando estresse, ansiedade e medo de consumir algo que prejudique o quadro clínico do bebê. As mães apontam a necessidade de melhorar a comunicação dos profissionais para com a família. Relataram que os profissionais não têm alinhamento nas respostas e 
destacaram a importância de a instituição promover reuniões periódicas com os pais, para oferecer apoio e melhorar a informação.

Na dimensão proximidade o desejo de ter mais contato com esse filho, principalmente no caso de gêmeos, pois a instituição não permite que a mãe tenha o contato equilibrado quando tem mais um bebê.

Houve também uma crítica ao INEFTI, aonde uma mãe relata que necessitaria terem cinco alternativas no inventário. Para que ela pudesse ter sido mais específica na resposta.

\section{CONCLUSÃO}

Avaliar as necessidades das mães com bebês internados na UTI neonatal, nos fez ampliar o olhar para essas necessidades. O estudo apresentou a importância de tomar conhecimento das necessidades das mães, para tornar o atendimento mais humanizado. Proporcionando conforto, segurança, informação, suporte, proximidade e bem-estar a elas.

$\mathrm{O}$ atendimento humanizado além de proporcionar o bem-estar as mães, promove como consequiência a melhora do bebê internado, pois a mãe se sentindo bem, estará em melhores condições de promover cuidado, carinho, atenção e o leite materno, que são fundamentais para a saúde do bebê. Por isso, sugerimos que outros estudos sejam realizados com uma amostra maior.

O inventário INEFTI aplicado neste estudo, tem condições de ser aplicado nas mães que tem seus bebês na UTI Neo, pois a mãe da UTI Neo é um familiar. Acrescentar a pergunta ao final do inventário foi extremamente válido, pois algumas mães puderam afirmar com maior expressão e especificidade algumas das suas reais necessidades, durante o período de internação dos bebês na UTI Neonatal. Com base nesses dados, já se pode fazer intervenções relevantes, tanto na estrutura, quanto na equipe, afim de levar um atendimento mais humano a essas mães, o que resultará em um melhor relacionamento, promovendo qualidade de vida para esses profissionais, mães e bebês. Proponho a implantação do Programa de Humanização e a adequação do Projeto Canguru, já iniciado na Unidade. 


\section{REFERÊNCIAS}

M. I. B. - Associação de Medicina Intensiva Brasileira, Humanização em Cuidados Intensivo: Revinter, 2004.

ARAÚJO, A. A.; Souza. A. B. G. A família na UTI neonatal. IN: SOUZA, A. B. G. (Org.), Unidade de Terapia Intensiva Neonatal- Cuidados ao Recém Nascido de Médio e Alto Risco. São Paulo: Atheneu, 2015.

AZEVEDO, C. S. PFEIL, N. V. No fio da navalha: a dimensão intersubjetiva do cuidado aos bebês com condições crônicas complexas. Physis: Revista de Saúde Coletiva, Rio de Janeiro, v. 29(4), e290406, 2019.

BELLINELLI, L. A., Lorenzini, E. A. Internação em Unidade de Terapia Intensiva e a família: perspectivas de cuidado. Avances en Enfermería, 27 (1), 15-21. Retrieved June 15, 2015, from http://www.scielo.org.co/scielo.php?script=sci_arttext\&pid=S0121-

$45002009000100002 \& \operatorname{lng}=$ en\&tlng=pt.

CARVALHO, M.,Gomes,M. A.S. A mortalidade do prematuro extremo em nosso meio: realidade e desafios. Jornal de Pediatria, Rio de Janeiro, 81(1 Supl), p.S111-S118, 2005.

CASTRO, D.S. Estresse e estressores dos familiares de pacientes com traumatismos crânio-encefálico em terapia intensiva. Tese - Escola de Enfermagem Anna Nery, Universidade Federal do Rio de Janeiro. Rio de Janeiro, 1999.

COSMO, M., Morsch, D., Goiaabeira, F., Genaro, L. e Aragão, P., O Paciente em Unidade de Terapia Intensiva- Critério de Atendimento Psicológico. IN: KITAJIMA. K (Org.), Psicologia em Unidade de Terapia Intensiva- Critérios e Rotinas de Atendimento. Rio de Janeiro: Revinter, 2014.

GRANDA, M. I. S., A Psicologia na Unidade de Neonatologia. IN: CAMOM, V.A.A. (Org.), Urgências Psicológicas no Hospital. São Paulo: Pioneira, 1998.

MATHELIN, C. O sorriso da Gioconda: Clínica Psicanalítica com Bebês Prematuros. Procopio Abreu. Rio de Janeiro: Companhia de Freud, 1999.160p.

SANTOS, L. C., Miranda, E. M. F., Nogueira, E. L. Psicologia, Saúde e Hospital- Contribuições para a Prática Profissional. Belo Horizonte: Artesã, 2015.

SOARES, M. (2007). Cuidando da família de pacientes em situação de terminalidade internados na unidade de terapia intensiva. Revista Brasileira de Terapia Intensiva, 19 (4), 481-484. Retrieved June 15, 2015, from http://www.scielo.br/scielo.php?script=sci_arttext\&pid=S0103507X2007000400013\&lng=en\&tlng=pt. 10.1590/S0103-507X2007000400013

SOLIMANI, RCS, PORTO JDS, SOUSA IF. Necessidades de Familiares de Pacientes Internados em UTI de um Hospital Universitário. 2015. Trabalho de Conclusão de Curso (Residência) - Programa de Residência Multiprofissional em Saúde do Hospital das Clínicas, Universidade Federal de Goiás, GoiâniaGO, 2015. 
WINNICOTT, D.W. Os bebês e suas mães. Tradução Jefferson Luiz Camargo. Revisão Técnica Maria Helena Souza Patto. 3. Ed. São Paulo: Martins Fontes, 2006.

WORLD HEALTH ORGANIZATION [Internet]. Geneva: WHO; c2018 [acesso em 2019 Dez 16]. Preterm birth. Disponível em: https://www.who.int/news-room/fact-sheets/detail/preterm-birth 